\title{
Desempenho de ovinos em sistema agroflorestal alternativo no ecótono Cerrado: Amazônia
}

\section{Sheep performance alternative agroforestry system in the Cerrado ecotone: Amazon}

\author{
SANTOS, Perlon Maia ${ }^{1 *}$; SANTOS, Antonio Clementino ${ }^{2}$; NEIVA, José Neumam \\ Miranda $^{3}$; NEVES NETO, Durval Nolasco ${ }^{4}$
}

\footnotetext{
${ }^{1}$ Universidade Federal Rural da Amazônia, Departamento de Zootecnia, Parauapebas, Pará, Brasil.

${ }^{2}$ Universidade Federal do Tocantins, Departamento de Solos, Araguaína, Tocantins, Brasil.

${ }^{3}$ Universidade Federal do Tocantins, Departamento de Produção Animal, Araguaína, Tocantins, Brasil.

${ }^{4}$ Instituto Tocantinense Presidente Antonio Carlos, Departamento de Estatística, Araguaína, Tocantins, Brasil.

*Endereço para correspondência: perllon_zoo@yahoo.com.br
}

\section{RESUMO}

Sistemas agroflorestais podem ser alternativa para a reincorporação de áreas em desuso, sob floresta secundária, para produção ovina. Com este estudo buscou-se avaliar o desempenho de ovinos em sistema silvipastoril de capimmombaça e floresta secundária de babaçu, comparando-o com o sistema convencional de produção a sol pleno. Nestes dois sistemas foram avaliadas as condições climatológicas e as características agronômicas e bromatológicas da gramínea. Nos animais foram avaliados o ganho de peso, o consumo, a conversão alimentar, os processos de deslocamento e a produtividade animal. Foi observado que a exploração ovina neste tipo de sistema silvipastoril é possível, mas há redução do desempenho animal em relação o sistema tradicional de exploração. $\mathrm{O}$ ambiente no sistema silvipastoril é quente e úmido, e a disponibilidade de forragem é baixa, fazendo com que os animais gastem mais energia para procurar alimento. $\mathrm{O}$ acúmulo de forragem e o perfilhamento no sistema silvipastoril são reduzidos e há diminuição da capacidade de suporte e produtividade. Apesar da redução da produtividade no sistema silvipastoril, sua exploração possibilita a produção de aproximadamente metade do que é produzido no sistema convencional.

Palavras-chave: ovinocultura, sistema silvipastoril, palmeira babaçu

\section{SUMMARY}

Agroforestry systems can be alternative to the reintroduction of areas into disuse, secondary forest, for sheep production. This study evaluated the performance of sheep integrated grass Mombasa and secondary forest of babassu, comparing it with the conventional system of production in full sun. In these two systems were evaluated the climatic conditions and the agronomic and qualitative characteristics of the grass. In animals were evaluated weight gain, consumption, feed conversion, displacement processes and animal productivity. It was observed that ovine silvipastoral in this type of system is possible, but there is a reduction of the animal performance over the traditional operating system. The environment in the integrated system is hot and humid, and the forage density is low, causing the animals to spend more energy to look for food. The accumulation of forage and tillering in the integrated system area reduced and there is reduced carrying capacity and productivity. Despite the reduction in productivity in the integrated system, its operation allows the production of approximately half of what is produced in the conventional system.

Keywords: sheep breeding, silvopastoral system, babassu palm 


\section{INTRODUÇ̃̃̃O}

A ovinocultura no Brasil apresenta importância secundária em relação à bovinocultura. Em 2012 o efetivo bovino superou 220.028.661 cabeças, enquanto o rebanho ovino alcançou a marca de 16.789.492 cabeças (IBGE, 2013). Uma alternativa para o aumento da produção ovina, seria a utilização de áreas improdutivas/ociosas, caracterizando um sistema alternativo de produção (POLI et al., 2008; SILVA NETO et al., 2015).

Áreas improdutivas são resultado de degradação agrícola. Nestas áreas pode ocorre restauração natural da vegetação, originando florestas secundárias (SILVA NETO et al., 2015). No ecótono Amazônia:Cerrado, que inclui o norte do Tocantins, existem $15 \%$ de floretas secundárias, e uma espécie de presença marcante nestas florestas é o Babaçu (Attalea speciosa, Mart). Esta espécie é passível de formar sistemas pecuários-florestais (CEPEM, 2010), logo, estas florestas de babaçu têm potencial para serem reincorporadas ao processo de produção, compondo sistemas silvipastoris, que podem ser explorados pela ovinocultura.

Os sistemas silpastoril (SSPs) possuem características ecológicas e conservacionistas (PACIULLO et al., 2011), e vários autores (VOUDOUHE, 2011; RIBEIRO et al., 2008; (SILVA NETO et al., 2015) citam os benefícios destes ambientes para a interface soloplanta-animal.

No atual estado da arte, SSPs estão incluídos em programas de desenvolvimento sustentável (MÜLLER et al. 2009; SILVA NETO et al., 2015) e programas de governo federal, no que se refere a fomento ao agronegócio, pela institui da política nacional de integração lavoura-pecuária-floresta.
Ainda, pesquisas com exploração ovina em SSPs têm gerado tecnologias (COSTA et al., 2015).

A possibilidade da formação de sistemas agroflorestais com pequenos ruminantes parece ser viável (HAWKE, 1993). Os estudos de Rai E Rai, (2010) revelaram que cordeiros apascentados em sistemas silvipastoris podem apresentar ganho de peso de $69 \mathrm{~g}$ dia- ${ }^{-1}$, e que o desempenho nestes sistemas pode ser $39 \%$ maior que numa pastagem convencional.

Diante do exposto, é notória a possibilidade de adoção da técnica de integração floresta-pasto para a reincorporação de áreas abandonadas para exploração da ovinocultura, de modo a gerar sistemas de produçãos ecologicamente corretos.

O objetivo com este estudo foi avaliar um sistema silvipastoril com espécies arbóreas nativas do ecótono Cerrado:Amazônico, caracterizando o pasto, o desempenho e a produtividade de cordeiros, em comparação com o um sitema convencional de exploração.

\section{MATERIAL E MÉTODOS}

A área experimental localiza-se na fazenda da Escola de Medicina Vetrinária e Zootecnia da Universidade Federal do Tocantins, Araguaína - TO, entre os paralelos 9213700 e 9213900 UTM-NS e meridianos 810500 e 810780 UTM-WE. De acordo com a classificação Köppen (1948) o clima da região é Aw (quente e úmido), com precipitações anuais médias de 1800 $\mathrm{mm}$, temperaturas máximas de $40{ }^{\circ} \mathrm{C} \mathrm{e}$ mínimas de $18{ }^{\circ} \mathrm{C}$. A umidade relativa do ar média anual é de $76 \%$. O solo da área experimental é classificado, (EMBRAPA, 2013) com Argissolo vermelho eutrófico. 
A área total tem histórico de abertura para implantação de pasto de mais de 25 anos. Foi abandonada após a degradação do pasto, dando origem a floresta secundária com forte presença da palmeira Babaçu (Attalea speciosa, Mart) em sua composição florística e uma capoeira (vegetação secundária composta por gramíneas e arbustos esparsos), caracterizada por espécies arbustivas de até $4 \mathrm{~m}$ de altura e diâmetro de $8 \mathrm{~cm}$.

$\mathrm{Na}$ área sob floresta de Babaçu foi estabelecido um sistema silvipastoril (SSP) com as espécies arbóreas nativas (Babaçu) e a capim-mombaça (Panicum maximum Jacq. cv. Mombaça). Estas áreas foram parcialmente desflorestadas, preservando-se as palmeiras até obter-se $30 \%$ de sombreamento (SSP 30): nível moderado de sombra Os processos de raleamento e níveis de sombreamento foram estabelecidos conforme Oliveira et al. (2013).

$\mathrm{O}$ ajuste do sombreamento foi realizado a partir da medida da iluminância (Lux) com o auxílio do luxímetro, modelo LD 200 Instrutherm (radiação global) em 50 pontos georreferenciados dentro do sistema. As leituras de luz foram realizadas entre as 11:30 a.m. e 13:00p.m., com sol a pino, sendo comparadas com leituras a sol pleno (SP), de forma simultânea. A partir destas mensurações foi calculada a porcentagem de sombreamento em cada área. As leituras ocorreram durante a abertura das áreas (raleamento), e periodicamente (em média a cada dois meses) durante o período experimental. Todos os procedimentos foram realizados conforme Silva Neto et al. (2015).

A área sob vegetação de capoeira foi roçada e tratada com herbicida, dando origem ao sistema convencional de produção à pasto: Sol Pleno (monocultivo de capim-mombaça), onde não haviam árvores. As dimensões de cada área (sistema) foram: Sol Pleno: $6.500 \mathrm{~m}^{2}$ e SSP 30: $7.042,2 \mathrm{~m}^{2}$.

Em ambos os sistemas o capimmombaça foi semeado em novembro de 2011, de forma manual, a lanço, a uma taxa de semeadura de $7 \mathrm{~kg}$ ha- ${ }^{1}$ de sementes puras viáveis (vc: 35\%). Adubações e correções foram realizadas conforme Silva Neto (2015) com base na análise de solo da área (camada 0-20 $\mathrm{cm}$ de profundidade): $\mathrm{MO}: 35,82 \mathrm{~g} \mathrm{dm}^{-3}$; pH: 5,$06 ; \quad$ P: $15,24 \mathrm{~g} \quad \mathrm{dm}^{-3} ; \quad \mathrm{K}$ : $60,54 \mathrm{cmol}_{\mathrm{c}} \mathrm{dm}^{-3}$; Ca: $9,40 \mathrm{cmol}_{\mathrm{c}} \mathrm{dm}^{3}$; $\mathrm{Mg}: 2,42 \mathrm{cmol}_{\mathrm{c}} \mathrm{dm}^{-3} ; \mathrm{H}+\mathrm{Al}: 3,78 \mathrm{cmol}_{\mathrm{c}}$ dm-3; Al: 0,0; SB: 11,97; CTC pH7: 15,75; V\%: 79,53; m\%: 0,0; Densidade Aparente: 0,98g cm- ${ }^{3}$; Areia: 53\%; Silte: 9\%; Argila: 38\%; Estoque de carbono: 70,20 Mg ha- ${ }^{1}$; Classe textural: Argilo-arenoso.

As condições climáticas dos sistemas foram monitoradas com estações meteorológicas portáteis modelo Tycon Tp-1080wc Pro Weatherstation - R. Os dados climáticos mensurados foram: umidade relativa do ar (\%), temperatura $\left({ }^{\circ} \mathrm{C}\right)$, pressão atmosférica (Hpa), velocidade do vento $\left(\mathrm{m} \mathrm{s}^{-}\right)$, rajadas de vento $\left(\mathrm{m} \mathrm{s}^{1}\right)$, vento frio $\left({ }^{\circ} \mathrm{C}\right)$, ponto de orvalho $\left({ }^{\circ} \mathrm{C}\right)$ e precipitação $(\mathrm{mm})$. Os dados individuais diários de cada sistema compuseram médias semanais (Tabela 1). As variáveis mensuradas e os processamentos dos dados foram realizados conforme Oliveira et al. (2013) e Ferreira et al. (2011).

Para avaliar as pastagens foram realizados, a cada 28 dias (1 ciclo), cortes do pasto a altura de $20 \mathrm{~cm}$ do solo. A taxa de crescimento e acúmulo de forragem foi mensurada pela técnica de gaiolas de exclusão, em área de $1 \mathrm{~m}^{2}$ gaiola $^{-1}$. Além das amostras das gaiolas foram coletadas 30 amostras do pasto por sistema, em pontos representativos da altura média, para quantificação da 
Rev. Bras. Saúde Prod. Anim., Salvador, v.17, n.4, p.584-598 out./dez., 2016 http://www.rbspa.ufba.br ISSN 15199940

massa instantânea de forragem disponível, em área de $0,5 \mathrm{~m}^{2}$. Em cada ponto de coleta ainda foi realizada a contagem de perfilhos e altura do pasto. O material colhido no pasto e nas gaiolas foi separado nos componentes morfológicos. As frações foram secas, e dos resultados de massa seca (MS) foram calculados os valores de taxa de acúmulo de folha, de colmo e material morto, expressos em g de MS m${ }^{-2}$ dia $^{-1} \mathrm{e}$ $\mathrm{kg}$ de MS ha ${ }^{-1} \mathrm{dia}^{-1}$, disponibilidade instantânea de forragem, expressa em $\mathrm{kg}$ de MS de folha ha ${ }^{-1}$ e $\mathrm{kg}$ de MS total de forragem ha ${ }^{-1}$, densidade de forragem e índice de área foliar.

Tabela 1. Valores médios semanais de condições climatológicas em área de monocultivo de capim-mombaça (Sol Pleno - SP) e de integração florestapasto: capim-mombaça + Babaçu com 30\% de sombreamento (Sistema Silvipsatoril - SSP 30)

\begin{tabular}{lccccccc}
\hline Área & Semanas & $\begin{array}{r}\text { Umidade } \\
(\%)\end{array}$ & $\begin{array}{c}\text { Temperatura } \\
\left({ }^{\circ} \mathrm{C}\right)\end{array}$ & $\begin{array}{c}\text { Velocidade } \\
\text { do Vento } \\
(\mathrm{m} / \mathrm{s})\end{array}$ & $\begin{array}{c}\text { Rajada } \\
\text { de vento } \\
(\mathrm{m} / \mathrm{s})\end{array}$ & $\begin{array}{c}\text { Vento } \\
\text { frio } \\
\left({ }^{\circ} \mathrm{C}\right)\end{array}$ & $\begin{array}{c}\text { Chuva/sema } \\
\text { na }(\mathrm{mm})\end{array}$ \\
\hline SP & $1^{\circ}$ & 66,01 & 22,18 & 0,51 & 1,41 & 21,66 & 35,32 \\
SP & $2^{\circ}$ & 82,45 & 26,08 & 0,44 & 1,29 & 25,37 & 96,34 \\
SP & $3^{\text {o }}$ & 85,73 & 25,62 & 0,66 & 1,79 & 25,55 & 103,99 \\
SP & $4^{\circ}$ & 78,06 & 24,63 & 0,53 & 1,50 & 24,19 & 78,55 \\
SP & $5^{\circ}$ & 86,70 & 26,62 & 0,86 & 2,12 & 25,42 & 14,30 \\
SP & $6^{\circ}$ & 91,31 & 25,81 & 0,62 & 1,66 & 25,63 & 23,85 \\
SP & $7^{\circ}$ & 87,65 & 25,19 & 0,52 & 1,40 & 24,78 & 32,33 \\
SP & $8^{\circ}$ & 82,56 & 25,16 & 0,59 & 1,59 & 24,66 & 29,66 \\
SP & $9^{\circ}$ & 92,63 & 23,82 & 0,18 & 0,91 & 23,58 & 47,24 \\
SP & $10^{\circ}$ & 89,12 & 26,21 & 0,80 & 1,93 & 25,84 & 46,72 \\
SP & $11^{\circ}$ & 91,12 & 26,40 & 0,68 & 1,71 & 25,97 & 49,52 \\
SP & $12^{\circ}$ & 97,02 & 25,39 & 0,11 & 0,64 & 25,16 & 80,30 \\
SSP 30 & $1^{\circ}$ & 86,22 & 27,44 & 0,25 & 0,97 & 26,55 & 35,32 \\
SSP 30 & $2^{\circ}$ & 82,16 & 26,02 & 0,44 & 1,25 & 25,15 & 96,34 \\
SSP 30 & $3^{\text {o }}$ & 84,67 & 26,14 & 0,46 & 1,39 & 25,75 & 103,99 \\
SSP 30 & $4^{\circ}$ & 86,03 & 25,55 & 0,67 & 1,22 & 25,49 & 78,55 \\
SSP 30 & $5^{\circ}$ & 84,51 & 27,11 & 0,66 & 1,16 & 25,53 & 14,30 \\
SSP 30 & $6^{\circ}$ & 87,95 & 29,92 & 0,35 & 0,93 & 28,61 & 23,85 \\
SSP 30 & $7^{\circ}$ & 88,54 & 25,20 & 0,17 & 0,78 & 24,74 & 32,33 \\
SSP 30 & $8^{\circ}$ & 88,54 & 25,20 & 0,17 & 0,78 & 24,74 & 29,66 \\
SSP 30 & $9^{\circ}$ & 92,34 & 25,09 & 0,33 & 1,11 & 23,90 & 47,24 \\
SSP 30 & $10^{\circ}$ & 90,58 & 26,15 & 0,70 & 1,51 & 25,81 & 46,72 \\
SSP 30 & $11^{\circ}$ & 97,20 & 25,59 & 0,20 & 0,78 & 32,71 & 49,52 \\
SSP 30 & $12^{\circ}$ & 97,20 & 25,59 & 0,20 & 0,78 & 32,71 & 80,30 \\
DesvPa & & 6,67 & 1,37 & 0,22 & 0,40 & 2,45 & 29,29 \\
\hline DSFPad: & & & & & & &
\end{tabular}

DesvPad.: desvio padrão.

As amostras do pasto referentes a fração folha, oriundas dos ciclos estudados, foram preparadas para a análise bromatológica segundo o manual de Silva \& Queiroz (2002) e foram feitas análises referente a proteína bruta, celulose, lignina, extrato etéreo, fibra em detergente neutro (FDN) e fibra em detergente ácido (FDA). 
Para a avaliação do desempenho animal foram introduzidos, em cada área, dez animais teste, sendo cinco ovinos machos castrados e 5 fềmeas, sem raça definida, deslanados, com peso médio de $21,45 \mathrm{~kg} \quad( \pm 2,25)$. Os animais passaram por período de adaptação às áreas de duas semanas. Neste período eles também foram adaptados a utilizar fraldas geriátricas e foram desverminados (Closantel - 1,5ml $10 \mathrm{~kg}$ $\left.\mathrm{PV}^{-1}\right)$. As áreas foram providas de cochos, bebedouros e abrigos.

O sistema de lotação contínua foi adotado como manejo das pastagens em ambas as áreas e o pasto foi mantido a $50 \mathrm{~cm}$ de altura. A oferta de forragem foi programada para $12 \mathrm{~kg}$ MS de lâmina foliar para cada $100 \mathrm{~kg}$ de peso vivo (12kg MSLF/100 kg PV) (SORIANO et al., 2013; MOREIRA et al., 2014). A carga animal foi determinada em função do suporte, obedecendo a oferta de forragem e sua taxa de crescimento (kg MSLF/dia TCC). Medidas de alturas (50 pontos), relacionadas com a oferta de MSLF auxiliaram na determinação da capacidade de suporte. Sempre que altura se desviava $10 \%$ da altura desejada ocorria entrada ou saída de animais reguladores.

A TCC para a área de Sol Pleno foi de $43 \mathrm{~kg}$ de MSLF dia ${ }^{-1}$. Isto permitiu o suporte dos dez animais teste e mais sete animais reguladores (total de dezessete animais em 0,65 hectares). A TCC para a área de SSP 30 foi de 25,3 $\mathrm{kg}$ de MSLF $\mathrm{dia}^{-1}$. Isto permitiu o suporte dos dez animais teste $(0,7$ hectares). Os cálculos de suporte e a entrada ou saída de animais foi realizada quinzenalmente em função das alturas e das disponibilidades de forragem.

A avaliação do desempenho dos animais foi realizada em intervalos de 28 dias, conforme Hawke (1993) durante três ciclos. Os animais passavam por jejum de 12 horas e eram pesados em balança digital. A diferença dos pesos inicial e final era o ganho de peso do período. Posteriormente foi calculado o ganho médio diário (GMD) em $g$ dia $^{-1}$.

Para quantificar o consumo de matéria seca (CMS) foi utilizado o protocolo de Penning e Hooper (1985), equacionado pela metodologia de tempo de pastejo de Costa et al. (2015). Na metodologia os animais usavam fraudas geriátricas e eram pesados antes e após um período de pastejo, sendo encontrado o consumo de forragem em função do tempo e do teor de MS do pasto. O protocolo se repetiu em cada período de avaliação.

A partir do CMS kg dia ${ }^{-1}$ foi calculado o consumo de MS em porcentagem do PV e a conversão alimentar (kg MS/kg PV). Para avaliar os padrões de deslocamento dos animais teste registrou-se o número de estações alimentares e número de passos dados entre as estações das 6:00 as 18:00 horas, simultaneamente em ambas as áreas conforme Oliveira et al. (2013), uma vez por ciclo. Cada animal foi avaliado individualmente durante 10 minutos. Ao final das avaliações dos animais, repetia-se o processo, de modo a gerar médias por animal. A partir dessas observações foi determinado o número de estações e o número de passos entre estações.

Os dados das características agronômicas e bromatológicas da forragem foram submetidos a análise fatorial $(2 \times 3)$ considerando os sistemas (SP e SSP 30) e os ciclos $\left(1^{\circ}\right.$ : novembro, $2^{\mathrm{o}}$ : dezembro e $3^{\mathrm{o}}$ : janeiro). Os pontos do grid de coleta de dados e as gaiolas foram usados como repetições. O teste de Tukey, a 5\% de probabilidade, foi usado para a comparação de médias. Quando verificada interações foi realizado o desdobramento dos fatores. O modelo 
matemático geral referente a cada resposta avaliada pôde ser representado pelo modelo linear aditivo:

$\mathrm{Y}_{\mathrm{ijk} k}=\mu+\mathrm{T}_{\mathrm{i}}+\beta_{\mathrm{j}}+(\beta \mathrm{T})_{\mathrm{jk}}+\varepsilon_{\mathrm{ijkl}}$ em que: $\mathrm{Y}_{\mathrm{ijkl}}=$ resposta de cada variável dependente; $\mu=$ média inerente as observações de cada resposta; $\mathrm{T}_{\mathrm{i}}=$ efeito do i-ésimo tratamento (Sol Pleno ou SSP 30$) ; \beta_{\mathrm{j}}=$ efeito do $\mathrm{j}$-ésimo ciclo; $\beta \mathrm{T}_{\mathrm{ji}}=$ efeito da interação ciclo $\mathrm{x}$ tratamento; $\varepsilon_{\mathrm{ijk}}=$ erro aleatório residual (variação do acaso sobre as observações).

Os dados das características relacionadas aos animais foram submetidos a análise fatorial $(2 \times 3 \times 2)$ considerando as áreas (tratamentos: SP e SSP 30$)$, os ciclos ( $1^{\circ}$ : novembro, $2^{\circ}$ : dezembro e $3^{0}$ : janeiro), e o sexo dos animais (macho e fêmea). Cada animal foi considerado como uma repetição. $\mathrm{O}$ teste de Tukey, a 5\% de probabilidade, foi usado par comparar as médias de desempenho e deslocamento dos animais. Quando verificada interações foi realizado o desdobramento dos fatores. $\mathrm{O}$ modelo matemático geral referente a cada resposta avaliada pôde ser representado pelo modelo linear aditivo:

$$
\mathrm{Y}_{\mathrm{ijk} l}=\mu+\mathrm{T}_{\mathrm{i}}+\beta_{\mathrm{j}}+\alpha_{\mathrm{k}}+(\beta \alpha)_{\mathrm{jk}}+(\mathrm{T} \alpha)_{\mathrm{ik}}+(\beta \mathrm{T})_{\mathrm{jk}}+\varepsilon_{\mathrm{ijk}}
$$

em que: $\mathrm{Y}_{\mathrm{ijkl}}=$ resposta de cada variável dependente; $\mu=$ média inerente as observações de cada característica; $\mathrm{T}_{\mathrm{i}}=$ efeito do i-ésimo tratamento (Sol Pleno ou SSP 30$) ; \beta_{\mathrm{j}}=$ efeito do j-ésimo ciclo; $\alpha_{\mathrm{k}}=$ efeito do k-ésimo sexo animal; $\beta \alpha_{j \mathrm{k}}=$ efeito da interação ciclo x sexo; $\mathrm{T} \alpha_{\mathrm{ij}}=$ efeito da interação tratamento $\mathrm{x}$ sexo; $\beta \mathrm{T}_{\mathrm{ji}}=$ efeito da interação ciclo $\mathrm{x}$ tratamento; $\varepsilon_{\mathrm{ijk}}=$ erro aleatório residual (variação do acaso sobre as observações).

Os dados de produtividade dos sistemas, referentes a taxa de lotação, número de cordeiros por hectare, ganho de peso vivo por hectare por dia, ganho de peso vivo por hectare por período $\mathrm{e}$ capacidade de suporte não foram submetidos a análise estatística, sendo apresentados somente seus valores médios pontuais.

Os dados meteorológicos foram comparados pelo teste $t$ (nível de significância de 0,1 ) para verificar $\mathrm{o}$ efeito do sistema silvipastoril - SSP 30 (grupo tratado) sob as condições climáticas, em relação ao tratamento a sol pleno - SP (grupo controle). Cada tratamento apresentou doze observações $(n=12)$, correspondente a cada semana, para cada característica ponderada.

\section{RESULTADOS E DISCUSSÃO}

A umidade relativa do ar e a temperatura foram superiores na área de integração floresta pasto (SSP 30) em relação a área a sol pleno (SP) (Tabela 2). Ao se calcular o índice de conforto (ITU índice de temperatura e umidade), conforme Ribeiro et al. (2008), foram observados valores de 69,46 para SP e 70,26 para SSP 30 (Tabela 2). O valor crítico de ITU para ovinos é de 71 (FERREIRA et al., 2011), logo, os animais apascentados na área SSP 30 estiveram mais afastados da zona de termoneutralidade.

A velocidade média dos ventos na área de SP foi superior a velocidade dos ventos na área SSP 30 (Tabela 2). Ribeiro et al. (2008) reporta velocidades dos ventos de 1,3 a $1,9 \mathrm{~m} \mathrm{~s}^{-1}$ como ideais para a criação de animais domésticos. Valores dentro desta faixa de recomendação foram observados na forma de rajadas de ventos 
na área SP $\left(1,49 \mathrm{~m} \mathrm{~s}^{-1}\right)$. A área SSP 30 apresentou ventos inferiores $\left(1,05 \mathrm{~m} \mathrm{~s}^{-1}\right)$ ao mínimo recomendado, fato que colaborou para a manutenção de maiores valores de umidade e temperatura. Resultados de menores velocidades dos ventos, maiores temperaturas e umidade do ar em SSPs são reportados por Soares et al. (2009), que alegam que as espécies arbóreas contribuem para que a temperatura não diminuía, devido à redução da troca de calor e perda de água.

Tabela 2. Médias trimestrais de condições meteorológicas em área de monocultivo de capim-mombaça (Sol Pleno - SP) e de integração floresta-pasto: capim mombaça + babaçu com 30\% de sombreamento (Sistema Silvipsatoril - SSP 30)

\begin{tabular}{|c|c|c|c|c|c|c|c|c|c|}
\hline Áreas & $\begin{array}{l}\text { UR } \\
(\%)\end{array}$ & $\left({ }^{\circ} \mathrm{C}\right)$ & $\begin{array}{c}\mathrm{PA} \\
(\mathrm{Hpa})\end{array}$ & $\begin{array}{c}\mathrm{Vv} \\
\left(\mathrm{m} \mathrm{s}^{-1}\right)\end{array}$ & $\begin{array}{c}\mathrm{Rv} \\
\left(\mathrm{m} \mathrm{s}^{1}\right)\end{array}$ & $\operatorname{VF}\left({ }^{\circ} \mathrm{C}\right)$ & $\begin{array}{c}\text { P.orv } \\
\left({ }^{\circ} \mathrm{C}\right)\end{array}$ & $\begin{array}{c}\text { Chuva } \\
\text { (mm) }\end{array}$ & ITU \\
\hline SP & $85^{\mathrm{b}}$ & $25,2^{b}$ & $959,3^{\mathrm{a}}$ & $0,54^{\mathrm{a}}$ & $1,49^{\mathrm{a}}$ & $24,8^{b}$ & $23,5^{\mathrm{a}}$ & $795^{\mathrm{a}}$ & 69,46 \\
\hline SSP 30 & $88^{\mathrm{a}}$ & $26,2^{\mathrm{a}}$ & $982,7^{\mathrm{a}}$ & $0,38^{\mathrm{b}}$ & $1,05^{\mathrm{b}}$ & $25,8^{\mathrm{a}}$ & $23,5^{\mathrm{a}}$ & $800^{\mathrm{a}}$ & 70,26 \\
\hline ns: & 10 & 10 & 5 & 10 & 1 & 5 & 5 & 5 & - \\
\hline $\mathrm{CV}$ & 12,68 & 9,51 & 27,17 & 18,49 & 26,9 & 8,83 & 6,87 & 5,68 & 2,59 \\
\hline
\end{tabular}

Letras iguais nas colunas diferem ao nível especificado. UR: umidade relativa do ar; ${ }^{\circ} \mathrm{C}$ : temperatura; PA: pressão atmosféria; Vv: velocidade do vento; Rv: rajadas de vento; VF: Vento frio; P.orv.: ponto de orvalho; ns: nível de significância; CV: coeficiente de variação; ITU: índice de temperatura e umidade.

O crescimento do pasto foi diferente entre os sistemas nos três períodos de avaliação (Tabela 3). A produção sempre foi maior na área SP, não havendo interações entre sistemas e ciclos. A média de acúmulo de MS de folhas dos três períodos no SP foi de $8,43 \mathrm{~g} \mathrm{~m}^{-2} \mathrm{dia}^{-1}$, superior a média de acúmulo no SSP 30: $3,6 \mathrm{~g} \mathrm{~m}^{-2} \mathrm{dia}^{-1}$. De modo geral, houve, no SSP 30, redução de $56,5 \%$ no crescimento do capimmombaça.

Os dados de produção de forragem deste estudo se assemelharam aos de Devkota et al. (2009), que avaliaram o crescimento de gramíneas sob sombreamento e encontraram reduções de até 59,63\%. Netes casos ocorre que, com o sombreamento, há redução da fotossíntese pela diminuição do total de ondas nos comprimentos do azul e vermelho.

As taxas de acúmulo de colmo foram semelhantes entre os sistemas nos três ciclos avaliados (Tabela 3). Isto pode estar relacionada ao fato de que no SSP 30 o sombreamento na base da touceira foi diminuído pela redução da densidade do dossel das plantas, (menor IAF), devido o sombreamento das árvores. Já no SP a maior densidade do dossel (maior IAF), elevou o acúmulo de colmos (ALEXANDRINO et al., 2011).

$\mathrm{O}$ número de perfilhos na área SP foi superior a área SSP 30 nos três ciclos avaliados (Tabela 3). No SSP 30 houve redução do perfilhamento de $51,9 \%$. O menor perfilhamento, provocou redução na densidade de forragem e no índice de área foliar (IAF). Segundo Belesky et al. (2011), a redução da quantidade e da qualidade da luz promove redução do perfilhamento, em parte porque há menos luz e foto assimilados para ativação das gemas (DEVKOTA et al., 2009).

Os valores de IAF no SSP 30 foram inferiores aos IAFs no SP, nos três ciclos avaliados (Tabela 3). Em média, o de IAF de SP foi $51,77 \%$ maior que o IAF de SSP 30. Este resultado é explicado pelo menor acúmulo de LF e perfilhamento no SSP 30. O fato de folhas de plantas sombreadas se tornarem mais alongadas, 
Rev. Bras. Saúde Prod. Anim., Salvador, v.17, n.4, p.584-598 out./dez., 2016 http://www.rbspa.ufba.br ISSN 15199940

menos espessas e menos largas (BELESKY et al., 2011), é outro fator que torna o dossel menos denso, e consequentemente, reduz o IAF.

A altura do pasto não diferiu entre os sistemas, nos três períodos avaliados (Tabela 3). Embora o estiolamento seja comum em plantas sob sombreamento
(SOARES et al., 2009), isso não se deu neste estudo, em parte porque $\mathrm{o}$ sombreamento no SSP 30 foi de moderado a abaixo. Logo, este nível de sombreamento compromete mais $\mathrm{o}$ perfilhamento que o alongamento de colmo e a relação folha:colmo.

Tabela 3. Características agronômicas e bromatológicas do capim-mombaça cultivado em pastagem convencional à sol pleno (SP) e em sistema Silvipastoril com $30 \%$ de sombreamento (SSP 30 )

\begin{tabular}{|c|c|c|c|c|c|c|c|}
\hline \multirow{2}{*}{$\begin{array}{l}\text { Sistemas } \\
\text { Ciclos }\end{array}$} & \multicolumn{3}{|c|}{ TAc folha (kg de MS ha- ${ }^{1}$ dia- $\left.^{1}\right)$} & \multicolumn{4}{|c|}{ TAc colmo (kg MS ha- ${ }^{-1}$ dia) } \\
\hline & $1^{\circ}$ & $2^{\circ}$ & $3^{\circ}$ & $1^{\circ}$ & & $2^{\circ}$ & $3^{\circ}$ \\
\hline SP & $78^{\mathrm{a}}$ & $104^{\mathrm{a}}$ & $71^{\mathrm{a}}$ & $13,3^{\mathrm{A}}$ & & $1,8^{\mathrm{B}}$ & $1,4^{\mathrm{B}}$ \\
\hline SSP 30 & $32^{\mathrm{b}}$ & $40^{\mathrm{b}}$ & $38^{\mathrm{b}}$ & $8,4^{\mathrm{A}}$ & & $1,7^{\mathrm{B}}$ & $0,9^{\mathrm{B}}$ \\
\hline \multirow[t]{2}{*}{ CV: 19,5} & \multicolumn{7}{|c|}{ CV: 68} \\
\hline & \multicolumn{3}{|c|}{ DIF folha ( $\mathrm{kg}$ de MS ha- $\left.{ }^{-1}\right)$} & \multicolumn{4}{|c|}{ DIF total (kg de MS ha- $\left.{ }^{1}\right)$} \\
\hline SP & $1119,2^{\mathrm{aB}}$ & $1839,7^{\mathrm{aA}}$ & $1752,4^{\mathrm{aA}}$ & $2615,6^{\mathrm{aB}}$ & $4153,8^{\mathrm{aA}}$ & & $3383,2^{\mathrm{aAB}}$ \\
\hline SSP 30 & $418,5^{\mathrm{b}}$ & $616,8^{\mathrm{b}}$ & $706,9^{\mathrm{b}}$ & $1430,7^{\mathrm{bA}}$ & $1118,6^{\mathrm{bA}}$ & & $1722,2^{\mathrm{bA}}$ \\
\hline CV: 30,1 & & & & CV: 28,01 & & & \\
\hline \multicolumn{4}{|c|}{ 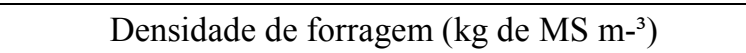 } & \multicolumn{4}{|c|}{ IAF } \\
\hline SP & $0,909^{\mathrm{aB}}$ & $1,774^{\mathrm{aA}}$ & $0,992^{\mathrm{aAB}}$ & $4,8^{\mathrm{a}}$ & $5,4^{\mathrm{a}}$ & & $3,9^{\mathrm{a}}$ \\
\hline SSP 30 & $0,539^{\mathrm{bA}}$ & $0,420^{\mathrm{bA}}$ & $0,477^{\mathrm{bA}}$ & $2,6^{\mathrm{b}}$ & $2,4^{\mathrm{b}}$ & & $2,3^{\mathrm{b}}$ \\
\hline \multirow[t]{2}{*}{ CV: 28,94} & \multicolumn{7}{|c|}{ CV: 28,5} \\
\hline & \multicolumn{3}{|c|}{ Número de perfilhos $\left(\mathrm{m}^{2}\right)$} & \multicolumn{4}{|c|}{ Alturas das plantas $(\mathrm{cm})$} \\
\hline SP & $645,5^{\mathrm{a}}$ & $690,5^{\mathrm{a}}$ & $567,2^{\mathrm{a}}$ & 52,7 & 52,6 & & 57 \\
\hline SSP 30 & $379,4^{\mathrm{b}}$ & $303,3^{\mathrm{b}}$ & $310,0^{\mathrm{b}}$ & 57,1 & 52 & & 53 \\
\hline CV: 22,53 & & & & CV: 16,8 & & & \\
\hline \multicolumn{8}{|c|}{ Bromatológica (\%) } \\
\hline & PB & FDN & FDA & Celulose & Lignina & Her & nicelulose \\
\hline $\mathrm{SP}$ & $10,8^{\mathrm{b}}$ & $64,9^{\mathrm{a}}$ & $37,3^{\mathrm{a}}$ & $39,2^{\mathrm{a}}$ & $6,06^{\mathrm{a}}$ & 26 & \\
\hline SSP 30 & $13,5^{\mathrm{a}}$ & $66,5^{\mathrm{a}}$ & $36,7^{\mathrm{a}}$ & $36,0^{\mathrm{b}}$ & $5,01^{\mathrm{b}}$ & 29, & \\
\hline $\mathrm{CV}$ & 13,28 & 4,64 & 7,09 & 6,51 & 51,57 & 13, & \\
\hline
\end{tabular}

$\mathrm{DIF}=$ disponibilidade instantânea de forragem. Minúsculas nas colunas e maiúsculas nas linhas. TAc $=$ Taxa de Acúmulo; DIF: Densidade instantânea de forragem; PB: Proteína bruta.

Os teores de proteína bruta (PB) nas lâminas foliares (LF) do capim no sistema SSP 30 foram superiores aos teores no SP (Tabela 3). Em média houve aumento de $20 \%$ no teor de PB no ambiente sombreado. Todavia a produção de $\mathrm{PB}$ $\mathrm{ha}^{-1}$ na área SSP 30 foi inferior à da área
SP, haja vista a menor produção de forragem. Este aumento da PB está relacionado a mineralização e ciclagem de nitrogênio (GOBBI et al., 2010) no SSP 30, bem como ao efeito de diluição, onde a maior produção de MS do SP causa incremento da parede celular e dilui 
o nitrogênio absorvido (SOARES, et al., 2009; GOBBI et al., 2010).

Os teores de FDN e FDA não diferiram entre os sistemas (Tabela 3). Isto pode ter ocorrido devido a avaliação ter sido feita apenas nas LF. A literatura documenta (TAIZER \& ZEIGER, 2012) que plantas sombreadas, por possuírem menor crescimento e maturação fisiológica, apresentam menos parede celular. Contudo, estes eventos não foram observados neste estudo, como observado também por Soares et al. (2009) e Paciullo et al. (2011).

A área SP apresentou maiores teores de celulose e lignina e menores teores de hemicelulose (Tabela 3). Logo, no SSP
30 foi depositada mais hemicelulose na parede celular. A hemicelulose funciona como uma matriz para a celulose. Ela causa o espaçamento entre as fibras. $\mathrm{O}$ maior alongamento da parede celular pode ser conseguido com o afastamento das fibras, devido o aumento da hemicelulose (TAIZER \& ZEIGER, 2012).

$\mathrm{O}$ desempenho dos animais na área SP foi superior ao SSP 30, nos três ciclos avaliados (Tabela 4). Não houve interação entre as áreas e sexo e entre ciclos e sexo para GMD. A falta de efeito do fator sexo está relacionada ao fato de os animais machos serem castrados, bem como por se tratar de animais jovens.

Tabela 4. Ganho médio diário - GMD ( $\left.\mathrm{g} \mathrm{dia}^{-1}\right)$ de ovinos apascentados em pastagem convencional de capim Mombaça a sol pleno (SP) e em sistema Silvipastoril com $30 \%$ de sombreamento (SSP 30)

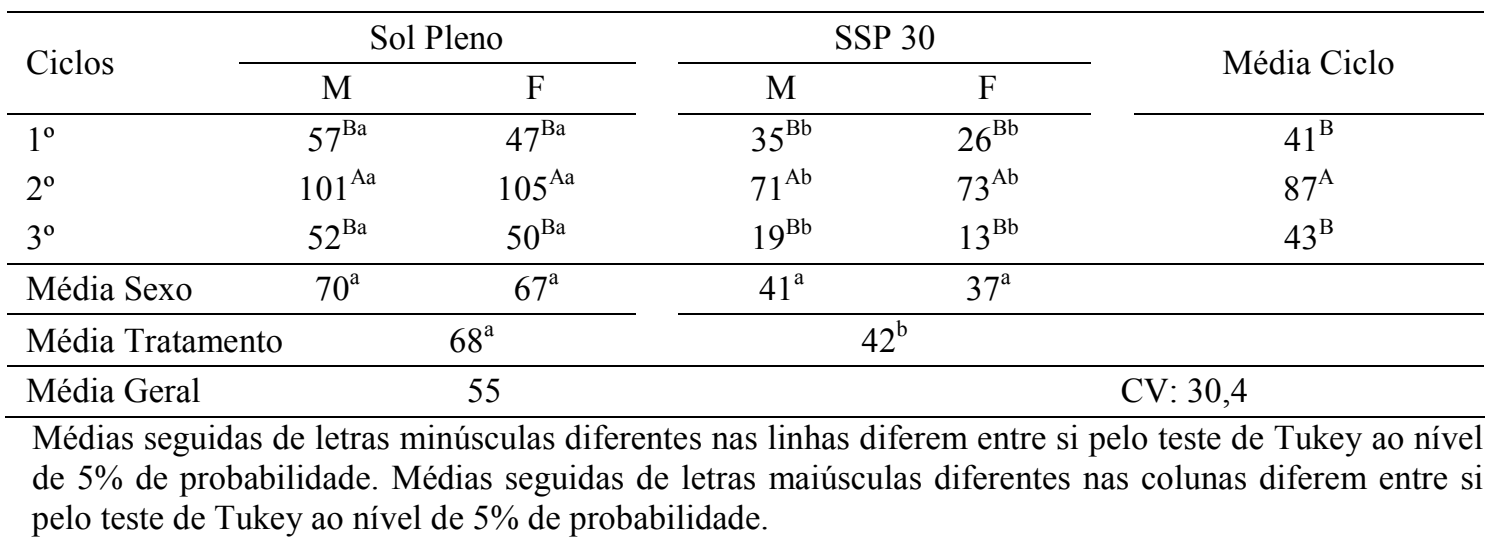

$\mathrm{Na}$ literatura é documentado que em ambientes sombreados ocorre maior desempenho animal (RAO et al., 2013; RAI \& RAI, 2010) No presente trabalho o resultado controverso pode estar relacionado ao fato que o sombreamento piorou a condição ambiental e reduziu a disponibilidade de forragem. Hawke et al. (1993), avaliando cordeiros em SSP também observaram menor desempenho destes animais em relação a animais criados em SP. Eles atribuíram a menor produção à piores ofertas de forragem, aumento do ataque de parasitas e ingestão de resíduos da floresta de baixa digestibilidade nestes SSP.

$\mathrm{O}$ consumo de forragem, em $\mathrm{kg}$ de MS $\operatorname{dia}^{-1}$, (Tabela 5), foi superior na área SP $(0,68)$ em relação a área SSP $30(0,61)$. O consumo não diferiu entre sexos e aumentou do $1^{\circ}$ para o $3^{\circ}$ ciclo. Foi observada interação entre os sistemas e os ciclos. No $1^{\circ}$ ciclo o consumo foi maior na área $\mathrm{SP}$, enquanto que no $2^{\circ}$ e $3^{\circ}$ ciclo, o consumo foi similar entre os dois sistemas. 
Rev. Bras. Saúde Prod. Anim., Salvador, v.17, n.4, p.584-598 out./dez., 2016 http://www.rbspa.ufba.br ISSN 15199940

O maior consumo de forragem no SP é explicado pela melhor condição do pasto (Tabela 3), embora a oferta de MSLF tenha sido igual nas duas áreas. Já no SSP 30 a menor disponibilidade de forragem fez com que os animais tivessem maior tempo de procura por alimento e menor ingestão. Isto parece ter sido mais intenso no $1^{\circ}$ ciclo, enquanto que no $2^{\circ}$ e $3^{\circ}$ ciclo, mudanças comportamentais podem ter elevado a eficiência de colheita, contudo, as custas de maior gasto de energia para pastejo, o que comprometeu o ganho de peso.

Tabela 5. Consumo voluntário de MS de forragem, expresso em $\mathrm{kg} \mathrm{dia}{ }^{-1}$, por ovinos apascentados em pastagem convencional de capim-mombaça a sol pleno (SP) e em sistema Silvipastoril com 30\% de sombreamento (SSP 30)

\begin{tabular}{|c|c|c|c|c|c|}
\hline \multirow{2}{*}{ Ciclos } & \multicolumn{2}{|c|}{ Sol Pleno } & \multicolumn{2}{|c|}{ SSP 30} & \multirow{2}{*}{ Média Ciclo } \\
\hline & $\mathrm{M}$ & $\mathrm{F}$ & $\mathrm{M}$ & $\mathrm{F}$ & \\
\hline $1^{\circ}$ & $0,51^{\mathrm{Ca}}$ & $0,62^{\mathrm{Ca}}$ & $0,45^{\mathrm{Cb}}$ & $0,45^{\mathrm{Cb}}$ & $0,52^{\mathrm{C}}$ \\
\hline $2^{o}$ & $0,65^{\mathrm{Ba}}$ & $0,65^{\mathrm{Ba}}$ & $0,61^{\mathrm{Ba}}$ & $0,62^{\mathrm{Ba}}$ & $0,66^{\mathrm{B}}$ \\
\hline $3^{\circ}$ & $0,73^{\mathrm{Aa}}$ & $0,83^{\mathrm{Aa}}$ & $0,77^{\mathrm{Aa}}$ & $0,71^{\mathrm{Aa}}$ & $0,76^{\mathrm{A}}$ \\
\hline Média Sexo & 0,66 & 0,70 & 0,61 & 0,61 & \\
\hline Média Tratamento & \multicolumn{2}{|c|}{$0,68^{\mathrm{a}}$} & \multicolumn{2}{|c|}{$0,61^{b}$} & \\
\hline Média Geral & \multicolumn{2}{|c|}{0,64} & & \multicolumn{2}{|c|}{ CV: 15,63} \\
\hline
\end{tabular}

Médias seguidas de letras minúsculas diferentes nas linhas diferem entre si pelo teste de Tukey ao nível de $5 \%$ de probabilidade. Médias seguidas de letras maiúsculas diferentes nas colunas diferem entre si pelo teste de Tukey ao nível de 5\% de probabilidade

Hawke (1993), também observou que a ingestão de MS por ovinos em SSP pode ser reduzida por fatores como a densidade do dossel, massa do bocado e a seleção no pastoreio, fatores que foram influenciados negativamente neste estudo, no SSP 30.

A conversão alimentar (CA) dos animais no SP foi melhor que a CA no SSP 30
(Tabela 6). Ao longo dos ciclos foi verificado que a melhor CA ocorreu no $2^{\circ}$ ciclo. Já a pior CA ocorreu no $3^{\circ}$ ciclo. Ainda, foi verificada interação ente os sistemas e os ciclos, onde se constatou que, apenas no $2^{\circ}$ ciclo, a CA foi semelhante entre os sistemas.

Tabela 6. Conversão Alimentar ( $\mathrm{kg}$ de $\mathrm{MS} / \mathrm{kg}$ de PV) de ovinos apascentados em pastagem convencional de capim-mombaça a sol pleno (SP) e em sistema Silvipastoril com $30 \%$ de sombreamento (SSP 30)

\begin{tabular}{|c|c|c|c|c|c|}
\hline \multirow{2}{*}{ Ciclos } & \multicolumn{2}{|c|}{ Sol Pleno } & \multicolumn{2}{|c|}{ SSP 30} & \multirow{2}{*}{ Média Ciclo } \\
\hline & $\mathrm{M}$ & $\mathrm{F}$ & $\mathrm{M}$ & $\mathrm{F}$ & \\
\hline $1^{\circ}$ & $10,20^{\mathrm{Ab}}$ & $11,54^{\mathrm{Ab}}$ & $16,69^{\mathrm{Aa}}$ & $23,07^{\mathrm{Aa}}$ & 18,33 \\
\hline $2^{\circ}$ & $8,42^{\mathrm{Ba}}$ & $8,09^{\mathrm{Ba}}$ & $9,22^{\mathrm{Ba}}$ & $10,29^{\mathrm{Ba}}$ & 9,00 \\
\hline $3^{\circ}$ & $14,52^{\mathrm{Ab}}$ & $15,92^{\mathrm{Ab}}$ & $52,08^{\mathrm{Aa}}$ & $70,50^{\mathrm{Aa}}$ & 38,26 \\
\hline Média Sexo & 10,99 & 11,85 & 25,99 & 38,62 & \\
\hline Média Tratamento & \multicolumn{2}{|c|}{$11,42^{\mathrm{b}}$} & \multicolumn{2}{|c|}{$32,31^{\mathrm{a}}$} & \\
\hline Média Geral & \multicolumn{2}{|c|}{21,86} & & \multicolumn{2}{|c|}{ CV: 14,54} \\
\hline
\end{tabular}

Médias seguidas de letras minúsculas diferentes nas linhas diferem entre si pelo teste de Tukey ao nível de 5\% de probabilidade. Médias seguidas de letras maiúsculas diferentes nas colunas diferem entre si pelo teste de Tukey ao nível de $5 \%$ de probabilidade. 
A pior CA no sistema SSP 30 (Tabela 6) está relacionada ao menor GMD (Tabela 4), e se deve, principalmente, as piores condições ambientais (Tabela 2) e ao aumento da procura por alimento, devido a menor densidade de forragem (Tabela 3), embora a forragem disponível apresentasse melhor valor nutricional (Tabela 3).

Os melhores valores de CA no $2^{\circ}$ ciclo podem estar associados à menor precipitação (Tabela 1), que tornou o ambiente mais propício ao pastejo. A similaridade entre os sistemas para CA, na ocorrência de um período de veranico ( $2^{\circ}$ ciclo), indica que a umidade é um dos maiores problema para ovinos em sistema silvipastoris.

Os piores valores de CA no SSP 30 no $3^{\circ}$ ciclo (Tabela 6), se devem a elevada precipitação (Tabela 1), que provocou pontos de alagamento no pasto, forçando os animais a intensificarem o pastejo em zonas e ingerirem alimento de pior qualidade. Hawke (1993) confirma que pontos de alagamento dentro de SSP prejudicam o pastoreio.

O número de estações alimentares em 10 minutos (EA-10) em SP foi inferior ao EA-10 no SSP 30 (Tabela 7). Não houve efeito do sexo e de ciclo. O maior número de EA-10 no SSP 30 revela a maior necessidade de troca de zonas de pastejo. Isto foi provocado pela baixa densidade de forragem, que obrigava o animal a mudar de local em função da baixa disponibilidade de lâminas foliares (Tabela 3) (FERREIRA et al., 2011).

Tabela 7. Processo de deslocamento em número de estações alimentares, durante 10 minutos, de ovinos apascentados em pastagem convencional de capim Mombaça a sol pleno (SP) e em sistema Silvipastoril com 30\% de sombreamento (SSP 30)

\begin{tabular}{|c|c|c|c|c|c|}
\hline \multirow{2}{*}{ Períodos } & \multicolumn{2}{|c|}{ Sol Pleno } & \multicolumn{2}{|c|}{ SSP 30} & \multirow{2}{*}{ Média Período } \\
\hline & $\mathrm{M}$ & $\mathrm{F}$ & $\mathrm{M}$ & $\mathrm{F}$ & \\
\hline Manhã & $10,4^{\mathrm{Bb}}$ & $12,2^{\mathrm{Bb}}$ & $13,6^{\mathrm{Ba}}$ & $17,6^{\mathrm{Ba}}$ & 13,45 \\
\hline Tarde & $16,6^{\mathrm{Ab}}$ & $15,4^{\mathrm{Ab}}$ & $20,6^{\mathrm{Aa}}$ & $24,0^{\mathrm{Aa}}$ & 19,15 \\
\hline Média Sexo & 13,5 & 13,8 & 17,1 & 20,8 & \\
\hline Média Tratamento & \multicolumn{2}{|r|}{$13,45^{\mathrm{b}}$} & \multicolumn{2}{|c|}{$17,10^{\mathrm{a}}$} & \\
\hline Média Geral & \multicolumn{2}{|r|}{15,27} & & \multicolumn{2}{|c|}{ CV: 27,35} \\
\hline
\end{tabular}

Gonçalves et al. (2009) e Ferreira et al. (2011) também observaram que sob menor disponibilidade de forragem havia aumento no número de EA realizados por cordeiros. Eles reportam que o animal, ao reconhecer um local com maior densidade de forragem potencial para bocados, permanece nele, colhendo apenas com movimento da cabeça e da mandíbula.

O número de passos (NPs) entre as EA na área SSP 30 foi superior ao NPs entre as EA na área SP (Tabela 8). Estes resultados revelam que a busca por forragem no SSP 30 era mais intensa, e que havia maior dificuldade do animal em eleger uma estação alimentar satisfatória. 
No SP, a maior disponibilidade de LF e a maior densidade de forragem, permitiam que o animal encontrasse outra zona de pastejo mais rapidamente.

Os estudos de Gonçalves et al. (2009) e as menções de Ferreira et al. (2011) com ovinos em diferentes ofertas de forragem revelam que sob maiores ofertas há redução do número de passos entre as estações. Hawke (1993) também verificou que a redução da disponibilidade de forragem em SSPs faz com que ovinos aumentem o deslocamento. De modo geral, a maior necessidade de deslocamento dos animais na área SSP 30, em busca de alimento, fez com que o desempenho fosse reduzido em relação área SP. No SSP 30, possivelmente, maior parte da energia obtida do pasto tenha sido utilizada na mantença.

Tabela 8. Processo de deslocamento em número de passos entre estações alimentares, de ovinos apascentados em pastagem convencional de capim Mombaça a sol pleno (SP) e em sistema Silvipastoril com 30\% de sombreamento (SSP 30)

\begin{tabular}{|c|c|c|c|c|c|}
\hline \multirow{2}{*}{ Período } & \multicolumn{2}{|c|}{ Sol Pleno } & \multicolumn{2}{|c|}{ SSP 30} & \multirow{2}{*}{ Média Período } \\
\hline & $\mathrm{M}$ & $\mathrm{F}$ & $\mathrm{M}$ & $\mathrm{F}$ & \\
\hline Manhã & $5,10^{\mathrm{Ab}}$ & $6,17^{\mathrm{Ab}}$ & $10,26^{\mathrm{Aa}}$ & $7,37^{\mathrm{Aa}}$ & 7,90 \\
\hline Tarde & $4,52^{\mathrm{Bb}}$ & $4,70^{\mathrm{Bb}}$ & $7,33^{\mathrm{Ba}}$ & $6,55^{\mathrm{Ba}}$ & 5,70 \\
\hline Média Sexo & 4,81 & 6,84 & 8,79 & 6,96 & \\
\hline Média Tratamento & \multicolumn{2}{|r|}{$5,82^{b}$} & \multicolumn{2}{|c|}{$7,87 \mathrm{a}$} & \\
\hline Média Geral & \multicolumn{2}{|r|}{6,84} & & \multicolumn{2}{|c|}{ CV: 25,24} \\
\hline
\end{tabular}

A produtividade na área SP foi maior que a produtividade da área SSP 30 , nos três ciclos avaliados (Tabela 9). A maior produtividade no SP está relacionada a maior produção de forragem (Tabela 3 ), que manteve maior taxa de lotação, bem como o maior ganho de peso dos animais mantidos nesta área. Apesar da menor produtividade do SSP $30 \mathrm{em}$ relação SP, deve-se ponderar que o SSP 30 era uma área ociosa, que passou a produzir, de forma mais sustentável, aproximadamente $50 \%$ do que se produziu no sistema convencional.

Bird et al. (2010) ao avaliaram a produtividade de ovinos em SSP e SP observaram que a produtividade diminuia linearmente com o aumento do número de árvores, em função do baixo crescimento da forragem, e que era necessário retirar exporadicamente os animais da áreas sob SSP. Eles observaram ganhos ha $^{-1}$ dia $^{-1}$ da ordem de $0,98,0,63,0,68$ e $0,43 \mathrm{~g}$ nos sistemas $0,60,200$ e 815 árvores ha $^{-1}$, valores parecidos aos encontrados em SSP 30 deste estudo.

A atividade pecuária ovina desenvolvida em sistema silvipastoril alternativo, com raleamento aleatório de floresta secundária no ecótono Cerrado:Amazônico é possível, mas há redução do desempenho animal em relação ao sistema tradicional de exploração.

O ambiente neste tipo de sistema pode ser quente e úmido, e a densidade de forragem baixa, fazendo com que os animais gastem mais energia para procurar alimento. 
Rev. Bras. Saúde Prod. Anim., Salvador, v.17, n.4, p.584-598 out./dez., 2016 http://www.rbspa.ufba.br ISSN 15199940

Tabela 9. Produtividade de ovinos apascentados em pastagem convencional de capim Mombaça a sol pleno (SP) e em sistema Silvipastoril com 30\% de sombreamento (SSP 30)

\begin{tabular}{|c|c|c|c|}
\hline & Tratamentos & Sol pleno & Sistema Silvipastoril \\
\hline Ciclo & Parâmetros & & \\
\hline \multirow{5}{*}{$1^{\circ}$} & Taxa de lotação (UA ha"-1) & 1,95 & 0,96 \\
\hline & Cordeiros ha" ${ }^{-1}$ & 32,70 & 14,28 \\
\hline & Ganho $(\mathrm{kg}) \mathrm{ha}^{-1} \mathrm{dia}^{-1}$ & 1,20 & 0,21 \\
\hline & Ganho (kg) ha-1 período $^{-1}$ & 33,63 & 5,92 \\
\hline & Suporte $\left(\mathrm{kg} \mathrm{ha}^{-1}\right.$ período $\left.^{-1}\right)$ & 880,00 & 432,00 \\
\hline \multirow{5}{*}{$2^{\circ}$} & Taxa de lotação (UA ha"-1) & 1,96 & 1,03 \\
\hline & Cordeiros ha ${ }^{-1}$ & 30,90 & 14,28 \\
\hline & Ganho $(\mathrm{kg}) \mathrm{ha}^{-1} \mathrm{dia}^{-1}$ & 1,45 & 0,51 \\
\hline & Ganho (kg) ha-1 período $^{-1}$ & 40,63 & 14,42 \\
\hline & Suporte $\left(\mathrm{kg} \mathrm{ha}^{-1}\right.$ período $\left.^{-1}\right)$ & 840,54 & 464,74 \\
\hline \multirow{5}{*}{$3^{\circ}$} & Taxa de lotação (UA ha ${ }^{-1}$ ) & 1,96 & 1,00 \\
\hline & Cordeiros ha"-1 & 29,09 & 14,28 \\
\hline & Ganho $(\mathrm{kg}) \mathrm{ha}^{-1} \mathrm{dia}^{-1}$ & 1,36 & 0,17 \\
\hline & Ganho $(\mathrm{kg}) \mathrm{ha}^{-1}$ período $^{-1}$ & 38,18 & 4,81 \\
\hline & Suporte $\left(\mathrm{kg} \mathrm{ha}^{-1}\right.$ período $\left.^{-1}\right)$ & 886,18 & 454,01 \\
\hline \multicolumn{4}{|c|}{ Médias } \\
\hline & Taxa de lotação (UA ha"-1) & 1,95 & 0,99 \\
\hline & Cordeiros ha ${ }^{-1}$ & 30,08 & 14,28 \\
\hline & Ganho $(\mathrm{kg}) \mathrm{ha}^{-1} \mathrm{dia}^{-1}$ & 1,33 & 0,29 \\
\hline & Ganho $(\mathrm{kg}) \mathrm{ha}^{-1}$ período $^{-1}$ & 37,48 & 8,38 \\
\hline & Suporte $\left(\mathrm{kg} \mathrm{ha}^{-1}\right.$ período $\left.^{-1}\right)$ & 868,90 & 450,25 \\
\hline
\end{tabular}

A produtividade do sistema silvipastoril é inferior ao sistema convencional. $\mathrm{O}$ acúmulo de forragem e o perfilhamento no sistema silvipastoril são reduzidos e há diminuição da capacidade de suporte.

Este tipo de sistema silvipastoril pode possibilitar a produção de aproximadamente metade do que é produzido no sistema convencional.

\section{AGRADECIMENTOS}

A Capes e ao PRONEX - Programa de apoio aos Núcleos de Excelência (SECT/TO e CNPq) pelo financiamento da pesquisa.

\section{REFERÊNCIAS}

ALEXANDRINO, E.; GOMIDE, J.A.; GOMIDE, C.A.M. Fluxo de biomassa e taxa de acúmulo de forragem em capimmombaça mantido sob diferentes alturas.

Revista Brasileira de Saúde e Produção Animal [online], v.12, n.1, p.59-71, 2011.

BELESKY, D,P,; BERNER, D.M.; RUCKLE, J.M. Tiller production in cocksfoot (Dactylis glomerata) and tall fescue (Festuca arundinacea) growing along a linght gradient. Grass and Forage Science, v.66, n.3, p.1-11, 2011. 
Rev. Bras. Saúde Prod. Anim., Salvador, v.17, n.4, p.584-598 out./dez., 2016 http://www.rbspa.ufba.br ISSN 15199940

BIRD, P.R.; KELLAS, J.D.; JACKSON, T.T.; KEARNEY, G.A. Pinus radiata and sheep production in silvopastoral systems at Carngham, Victoria, Australia.

Agroforest System, v.78, n.3, p.203216, 2010.

CEPEM. Centro de Pesquisas Econaturais: Disponível em:

$<\mathrm{http}$ :/Www.cepen.com.br/arv_nat_gloss ario_ho.htm>. Acesso em: 01 out. 2010.

COSTA, J.V.; OLIVEIRA, M.E.; MOURA, R.M.A.S.; COSTA JÚNIOR, M.J.N.; RODRIGUES, M.M.

Comportamento em pastejo e ingestivo de caprinos em sistema silvipastoril. Revista Ciência Agronômica, v.46, n.4, p.865$872,2015$.

DEVKOTA, N.R.; KEMP, P.D.; HODGSON, J.; VALENTINE, I.; JAYA, I.K.D. Relationship between tree canopy height and the production of pasture species in a silvopastoral system based on alder trees. Agroforest System, v.76, n.2, p.363-374, 2009.

\section{EMBRAPA. Sistema Brasileiro de} Classificação de Solos. Centro nacional de pesquisa em solo. 3.ed. Brasília, DF, 2013. 353p.

FERREIRA, R.A.; ESTRADA, L.H.C.; THIÉBAUT, J.T.J.; GRANADOS, L.B.C.; SOUZA JÚNIOR, V.R. Avaliação do comportamento de ovinos Santa Inês em sistema silvipastoril no norte fluminense. Revista Ciência e Agrotecnologia, v.35, n.2, p.399-403, 2011.

GOBBI, K.F.; GARCÍA, R.; GARCEZ NETO, A.F.; PEREIRA, O.G.; ROCHA,

MÜLLER, D.M.; FERNANDES, E.N.; CASTRO C.R.T.; PACIULO, D.S.C.; ALVES, F.F. Estimativa e acúmulo de biomassa em sistema agrosilvipastoril na
G.C. Valor nutritivo do capim-braquiária e do amendoim forrageiro submetidos ao sombreamento. Archivos de Zootecnia, v.59, n.227, p.379-390, 2010.

GONÇALVES, E.D.; CARVALHO, P.C.F.; DEVINCENZI, T.; LOPES, M.L.T.; FREITAS, F.K.; JACQUES, A.V.A. Relações planta-animal em ambiente pastoril heterogêneo: padrões de deslocamento e uso de estações alimentares. Revista Brasileira de Zootecnia, v.38, n.11, p.2121-2126, 2009.

HAWKE, M.F.; RATTRAY, P.V.; PERCIVAL, N.S. Liveweight changes of sheep grazing a range of herbage allowances under Pinus radiata agroforestry regimes. Agroforest System, v.23, n.1, p.11-21, 1993.

SORIANO, V.S.; KOZLOSKI, G.V.; QUADROS, F.LF.; PIRES, C.C.; GRIEBLER, L. Produção animal e vegetal em pastagem de Cynodon manejada sob diferentes ofertas de forragem por ovinos de dois grupos genéticos. Revista Ciência Rural, v.43, n.1, p.145-150, 2013.

IBGE. Instituto Brasileiro de Geografia e Estatística.

$<$ www.ibge.gov.br/home/estatistica/econ omia/ppm/.../tab17.pdf>. Acesso: 5 out. 2013.

MOREIRA, A.L.; FAGUNDES, J.L.; YOSHIHARA, E.; BACKES, A.A.; BARBOSA, L.T.; HEINRICHS, R. Production of sheep grazing on nitrogenfertilized tifton 85 grass in continuous stocking. Acta Scientiarum. Animal Sciences, v.36, n.1, p.63-69, 2014.

Zona da Mata Mineira. Pesquisa Florestal Brasileira, v.10, n.60, p.11-17, 2009. 
Rev. Bras. Saúde Prod. Anim., Salvador, v.17, n.4, p.584-598 out./dez., 2016 http://www.rbspa.ufba.br ISSN 15199940

OLIVEIRA, F.A.; TURCO, S.H.N.; ARAÚJO, G.G.L.; CLEMENTE, C.A.A.; VOLTOLINI, T.V.; GARRIDO, M.S. Comportamento de ovinos da raça Santa Inês em ambientes com e sem disponibilidade de sombra. Revista Brasileira de Engenharia Agrícola e Ambiental, v.17, n.3, p.346-351, 2013.

PACIULLO, D.S.C.; CASTRO, C.R.T.; GOMIDE, C.A.M.; MAURÍCIO, R.M.; PIRES, M.F.A.; MÜLLER, M.D.; XAVIER, D.F. Performance of dairy heifers in a silvopastoral system.

Livestock Science, v.10, n.5, p.1-12, 2011.

PENNING, P.D.; HOOPER, G.E. An evaluation of the use of short-term weight changes in grazing sheep for estimating herbage intake. Grass Forage Science, v.40, n.1, p.79-84, 1985.

POLI, C.H.E.C.; MONTEIRO, A.L.G.; BARROS, C.S.; MORAES, A.; FERNANDES, M.A.M.; PIAZZETTA, H.V.L. Produção de ovinos de corte em quatro sistemas de produção. Revista Brasileira de Zootecnia, v.37, n.4, p.666-673, 2008.

RAI, A.K.; RAI, P. Performance of lambs and kids on silvipastoral system and effects of grazing on constituent vegetation. Range Management and Agroforestry, v.31 n.2, p.102-108, 2010.

RAO, G.R.; RAMANA, D.B.V.; PRASAD, J.V.N.S.; VENKATESWARLU, B. Performance of Deccani ram lambs grazed on stockpiled forage from established silvipasture. Range Management and Agroforestry, v.34, n.1, p. 93-97, 2013.

RIBEIRO, N.L.; FURTADO, D.A.; MEDEIROS, A.N.; RIBEIRO, M.N.; SILVA, R.C.B.; SOUZA, C.M.S. Avaliação dos índices de conforto térmico, parâmetros fisiológicos e gradiente térmico de ovinos nativos.

Revista Engenharia Agrícola, v.28, n.4, p.614-623, 2008.

SILVA, D.J.; QUEIROZ, A.C. Análise de alimentos: métodos químicos e biológicos. 2.ed. Viçosa, MG: UFV, 2002. 165 p.

SILVA NETO, S.P.; SANTOS, A.C.; LEITE, R.L.; SILVA, J.E.C.; NEVES NETO, D.N.; RODRIGUES, M.O.D.; ALENCAR, N.M. Integrating forestpasture: Spatial analysis and delineation of zones of litter production and nutrient return. Revista Semina: Ciências Agrárias, v.36, n.6, p.4377-4400, 2015.

SOARES, A.B.; SARTOR, L.R.; ADAMI, P.F.; VARELLA, A.C.; FONSECA, L.; MEZZALIRA, J.C. Influência da luminosidade no comportamento de onze espécies forrageiras perenes de verão. Revista Brasileira de Zootecnia, v.38, n.3, p.443-451, 2009.

TAIZER, L.; ZEIGER, E. Fotossíntese: as reações luminosas In: TAIZER, L.; ZEIGER, E. Fisiologia vegetal. 5.ed. Porto Alegre: Armed. 2012. Cap.8, p.139169.

VOUDOUHE, G. F.; COULIBALY, O.; BIAOU, G.; SINSIN, B. Traditional agroforestry systems and biodiversity conservation in Benin (West Africa). Agroforestal System, v.82, n.1, p. 1-13, 2011.

Data de recebimento: 11/05/2015

Data de aprovação: 07/10/2016 